\title{
An Analysis of Linguistic Features of the Multiplication Tables and the Language of Multiplication
}

\author{
Emily Sum ${ }^{1 *}$, Oh Nam Kwon ${ }^{1}$ \\ ${ }^{1}$ Seoul National University, Seoul, SOUTH KOREA
}

Received 8 January 2018 • Revised 26 March 2018 • Accepted 18 April 2018

\begin{abstract}
This study analyses the linguistic features of Korean language in learning multiplication. Ancient Korean multiplication tables, Gugudan, as well as mathematics textbooks and teacher's guides from South Korea were examined for the instruction of multiplication in second grade. Our findings highlight the uniqueness of the grammatical features of numbers, the syntax of multiplication tables, the simplicity of language of multiplication in Korean language, and also the complexities and ambiguities in English language. We believe that, by examining the specific language of a topic, we will help to identify how language and culture tools shape the understanding of students' mathematical development. Although this study is based on Korean context, the method and findings will shed light on other East Asian languages, and will add value to the research on international comparative studies.
\end{abstract}

Keywords: cultural artefacts, Korean language, linguistic features, multiplication tables

\section{INTRODUCTION}

Hong Kong, Japan, South Korea and Singapore have maintained their lead in international league tables of mathematics achievement such as TIMSS and PISA. Numerous comparative studies have been undertaken in search of the best East Asian practices and factors that have contributed to high student achievement; researchers have argued that one of the major factors behind the superior performance in cross-national studies is based on the underlying culture (e.g. Leung, 2001, 2002, 2006). One major element of culture is language, and Leung (1989) believed that there are characteristics in the Chinese language which might have contributed to Chinese students' superior performance in mathematics achievement. The abstract nature of mathematics content and the use of Arabic numerals may be universal, but the system of numbers and the expression of mathematical ideas vary across languages. The clarity with which the naming of numbers reflects the logic behind the base-ten number system varies considerably across cultures. Besides the number words, the Lexicon Project used lexicons as tools to integrate, enhance and advance comparative classroom research, and to identify both similarities and differences in the pedagogical principles and distinctions encrypted in different lexicons (Clarke, 2013). Yet, lexical ambiguities do not fully account for the variations of linguistic ambiguities that students face in mathematics. Schleppegrell (2007) discussed the complexity of mathematical language and linguistic challenges in mathematics learning, and highlighted the need to expand our understanding of language issues in mathematics beyond the focus on vocabulary or specified terminology.

Studies on the understanding of possible linguistics influences on students' early learning of school mathematics have been mainly confined to the computational topics of addition and subtraction. Limited research has been done regarding the language instruction of multiplication (e.g. Anghileri, 1991), especially the acquisition of multiplication facts. Formal instruction on multiplication generally starts in the second year of elementary school after addition and subtraction have been taught. A good understanding of multiplication is fundamental in elementary school mathematics as it plays a vital role in a student's development of more advanced mathematical concepts in multiplicative conceptual fields, such as ratio, rate, fraction, rational number, dimensional analysis and other functional relations (Confrey, 1994; Vergnaud, 1983, 1988). Stephens, Ellis, Blanton, and Brizuela (2017)

(C) 2018 by the authors; licensee Modestum Ltd., UK. This article is an open access article distributed under the terms and conditions of the Creative Commons Attribution License (http://creativecommons.org/licenses/by/4.0/). $\square$ siwan@snu.ac.kr (*Correspondence) $\square$ onkwon@snu.ac.kr 


\section{Contribution of this paper to the literature}

- This study examines the cultural and language aspects of learning multiplication in South Korea. Dual number systems, ancient multiplication tables and school textbooks were examined based on a linguistic approach, where distinguishable characteristics have been identified.

- The use of classifiers, the absence of plural marking, passive voice and other language features in Korean, make the language of multiplication, as well as the problem situations, easier to understand and comprehend.

- We believe the study of the functionality of the natural languages in mathematics learning, and the possible language difficulties facing learners require more attention.

pointed out that much instructional time in elementary mathematics is devoted to developing fluency with multiplication, including learning multiplication facts.

From the language perspective, the way we read multiplication tables such as $3 \times 4=12$ varies in different languages. Students need to recall multiplication fact families to solve multiplication and division situated problems. For example: 'three groups of four', they need to recall the corresponding number facts for three, that is 3 times 4 , in order to answer the question. It is therefore important for us to recognise the features of the numerals and lexicon in order to make the connections of the multiplication fact families and the problem situations. The set of times tables used in South Korea is known as Gugudan (구구단, means nine-nine table). It has a very long history and is deeply rooted in Korean society. Children are taught to recite Gugudan as a poem or song, where the digit names have the rhythm and analogous features of rhythmic poetry. This study is influenced by Whorf's (1956) linguistic relativity hypothesis - the structure of a language can affect the thought process of speakers of that language, which suggests that the thinking processes of the speakers of one language will differ from those of a speaker of any other language. As culture, language and cognition are intertwined in a complex manner, we believe becoming aware of the differences between languages may allow us to have a different perspective on mathematics education. Our focus is on the linguistic features of number systems, multiplication tables and the language of multiplication, which serves as the basis for our wider research study on investigating the intricate relationship between culture, language and mathematics learning.

\section{LITERATURE REVIEW}

There is increased recognition of the difficulty that many students have with mathematical language and the importance of language in learning mathematics (e.g. Morgan, Craig, Schutte, \& Wagner, 2014). Researchers have started to explore the role of language in explaining the relatively superior performance of Chinese and other East Asian students in cross-national studies (see Ng \& Rao, 2010). Studies showed that the linguistic features and number naming structures in Chinese language have influences on children's acquisition of mathematical concepts and later development (e.g. Miller, Kelly, \& Zhou, 2005). While the clarity of Asian languages (e.g. Japanese, Korean, Thai, Burmese) has been identified to have helped to speed up initial learning of number concept and increased the understanding that occurs in classroom discourses using clear words (e.g. Fuson \& Kwon, 1991; Fuson \& Li, 2009), many believed the base-ten number system provides linguistic support to the learning of arithmetic operations involving the concept of place value (Fuson, 1990; Miura \& Okamoto, 2003; Miura, Okamoto, Kim, Steere, \& Fayol, 1993; Song \& Ginsburg, 1985). In addition, Miura and Okamoto (2003) believed the use of numeral classifiers in Japanese, as part of the arithmetic story problem, may diminish ambiguity by making the referent clear. Recent study by Her, Chen and Yen (2018) on Chinese numeral classifiers showed, linguistically, classifiers highlight the inherent semantic attributes of the noun, and the linguistic system of classifiers interacts with categorization and magnitude cognition. Their findings also showed classifiers and measure words with mathematical values elicit higher neural (brain) activities for processing quantity information, which suggests that the system of classifiers is part of magnitude cognition that encodes the mathematical values (Her, 2012). The general classifier 개 ( $\mathrm{g} a \mathrm{e}$ ) is a Sino-Korean word associated with the Chinese character 個 ( $\mathrm{go}$ ). In fact, many Korean classifiers are derived from Chinese classifiers, and the grammatical use of classifiers is similar.

In the learning of multiplication, Japanese children are required to learn and recite the Kuku (means nine-nine) method of multiplication in elementary school, and it has been shown the Japanese kuku multiplication chart is an effective aid to perform arithmetic operations, and adults were found to solve multiplication problems more easily as compared to addition problems (Ito, Kubo-Kawai, \& Masataka, 2011). Similar findings were also made in graduate students from China who were studying at Canada, who performed better in solving single-digit multiplication problems compared with their Canadian counterparts (LeFevre \& Liu, 1997).

Studies on East Asian mathematics education place considerable focus on Chinese learners (e.g. Fan, Wong, Cai, \& Li, 2004; 2015; Ho \& Fuson, 1998; Miller, Kelly, \& Zhou, 2005; Miller \& Stigler, 1987). Nonetheless, Kwon and 
Cho (2012) believed that some studies on Asian education have mistakenly assumed that mathematics education in South Korea is almost the same as that in other East Asian countries. Thus far, relatively little has been written about Korean language and mathematics learning, and limited research has been devoted to the area of mathematics content: counting in two different numbers systems (Song \& Ginsburg, 1985, 1986), and addition and subtraction problems with single (Fuson \& Kwon, 1992a) and multi-digit numbers (Fuson \& Kwon, 1992b).

\section{CONCEPTUAL FRAMEWORK}

Research on linguistic complexity addresses the impact of lexicogrammatical structure on mathematical thinking; it is not just whether a certain concept can be expressed in a certain language, but the ease of expression of the concept: that is how the words and structures facilitate or impede expression. Introduced by Halliday, lexicogramma is a term used in Systemic Functional Linguistics (SFL). To him, grammar means lexicogrammar; that is, it includes vocabulary. The grammatical (lexicogrammatical) system is the system of what the speaker can say; and the lexicogrammatical system, as a whole, operations as the realization of the semantic system, which is what the speaker can mean (Halliday, 1978). One way of describing the relation between mathematics and languages is in terms of the linguistic notion of register, i.e. the language we speak or write varies according to the types of situation, and the theory of register is to attempt to uncover the general principles which govern this variation, in order to understand which situational factors determine which linguistic features (ibid). Halliday believed every language embodies some mathematical meanings in its semantic structure - ways of counting, measuring, classifying and so on. His linguistic notion of register and the sociolinguistic aspect of mathematical education underpins this research study. Mathematics register is the sense of meanings that belong to the language of mathematics (the mathematical use of natural language, that is: not mathematics itself), and that a language must express if it is being used for mathematical purposes. Mathematics register has specific vocabularies, and their development can be marked in various ways including: 1 . Creating words out of native word or non-native word stock (such as Greek and Latin); 2. Borrowing words from another language (the method most favoured in Korea).

Words like fraction (분수), algebra (대수) and geometry (기하) are borrowed from Chinese; 3. Reinterpreting existing everyday words with specific mathematics meaning. The ease with which a mathematics register develops depends, in part, on the grammatical system of the natural language. As mentioned, Chinese-based regular numbering systems have shown many advantages in early mathematics learning (Fuson \& Kwon, 1991; Miller \& Stigler, 1987; Miura \& Okamoto, 2003). For instance, short single-syllable number words reduce the burden on working memory (see $\mathrm{Ng} \&$ Rao, 2010); and base-ten system supports the understanding of place value and learning of addition and subtraction (e.g. Geary, Bow-Thomas, Fan, \& Siegler, 1993). Barton (2009) believed that the reason some languages find certain mathematical expressions, or uses of numbers, far easier to deal with than others may be due to the varied syntactic roles of numbers in different languages, i.e. whether numbers operate as nouns, verbs or adjectives. For example, the absence of singular and plural forms of nouns in Korean and Japanese, and the way numbers operate varies in numeral classifier languages (Allan, 1977) make numbers more transparent. Classifiers are words that suffix to a numeral when counting and they are used extensively in Korean (Lee \& Lee, 2009) and Japanese (Downing, 1996).

On the other hand, the linguistic challenges of the language of multiplication in English had been discussed in Anghileri (1991); in particular, the choice of wordings associated with multiplication symbols, where different interpretations are known to exist, and the ambiguity when attaching meaning to symbolic arithmetic expressions present considerable barriers to children's understanding. Additional confusion may arise with use of vocabularies in multiplication such as 'times', 'multiplied by', 'multiply by' etc. Concepts of numbers, of multiplication and division may be variously highlighted in the semantics of different languages. Research on the semantic aspect of mathematical language mainly focuses on mathematical problems (Solano-Flores, 2010), and the popular introduction for the concept of multiplication usually involves a variety of multiplicative situations that embody the operations. Greer (1992) believed that the most important classes of situations involving multiplication and division of integers are: equal groups, multiplicative comparison, Cartesian product and rectangular array (area). Watanabe (2003) used Greer's framework and found different emphases were placed in textbook series from Japan and the United States, suggesting cultural differences in terms of the teaching of multiplication.

In this section, we have discussed the mathematics register and research in language and mathematics education. Mathematics register allows us to express our mathematical understanding, ideas, and to communicate with one another. Thus, we must share the same mathematical meanings of words and expressions. We viewed Gugudan as mathematics register, which has the power to conjure a complex web of ideas that make up the mathematical concept to solve problems. It is a way of using language to express mathematical concepts and even characterize the mode of presenting multiplication operations. We considered Gugudan as a cultural artefact and the recitation of Gugudan is a sociocultural activity that represents the sediment of past learning that is effective and useful; therefore, it becomes part of the social action without any conscious planning. As long as the actions remain habitual, we seldom pause to ask about the values they serve, and do not need any justification as long as 
Table 1. Linguistic Factors in Mathematics Education

\begin{tabular}{|c|c|c|}
\hline & Language as System & Aspects of Investigation \\
\hline \multirow{3}{*}{$\begin{array}{l}\text { Lexico-grammar (words } \\
\text { and structures) }\end{array}$} & Vocabulary (words) & Number words, bea 배 and multiply 곱하기 \\
\hline & Morphology (word structures) & Nouns, numeral classifiers and plural marking \\
\hline & $\begin{array}{c}\text { Syntax (sentence and phrase structure - word } \\
\text { order) }\end{array}$ & Number sentences \\
\hline Semantics (meanings) & Arguments \& single items & Word problems \\
\hline Symbols & $\begin{array}{l}\text { Degree and kind of fit between verbal expression } \\
\text { and mathematical notation }\end{array}$ & $x$ \\
\hline
\end{tabular}

we are not called to account by others or abrupt changes in the circumstances in which we act. Hence, we could like to take a linguistic approach in understanding the learning of multiplication and our research questions are:

i. What are the linguistic features of Korean numerals? How are Korean multiplication tables read?

ii. What are the lexicogrammatical and semantic features in the language of multiplication?

\section{RESEARCH METHOD}

We have adopted the document analysis as a qualitative research method for this study. We collected and reviewed several classical texts on mathematics including the Ten Treatises of Mathematical Classics (산경십서 算經 十書), the Nine Chapters on the Mathematical Arts (구장산술 九章算術) and Introduction to Mathematical Studies (신편 산학계몽 총괄 新編算學啓蒙總括); as well as the elementary mathematics textbook series and the teacher's guide in South Korea. We extracted language data with the aspects of multiplication given in these documents, and examined the words and sentences in the mathematical text. We considered language as a system and adopted the analytical framework suggested by Halliday (1978, p.204) as shown in Table 1 in analysing the followings documents:

(1) Introduction to Mathematical Studies (신편 산학계몽 총괄, 新編算學啓蒙總括), written by Zhu Shijie (주세걸 朱世傑) in Yuan Dynasty, is one of the most influential classical mathematics books transmitted from China to Korea. It was used as the core text for the civil examinations during the Choson Dynasty. The book contains the multiplication tables, Gugudan (see Figure 2), that are still used today in South Korea. It was lost and only appeared again in the nineteenth century in China, and it did not seem to have any impact on the Chinese mathematical development (Chemla, 2008). We consider Gugudan as a mathematics register, and a cultural tool for mental calculation which has been passed down from generation to generation.

(2) Mathematics (수학) is the elementary mathematics textbook series developed and published by the Ministry of Education, and used in elementary schools throughout South Korea. Each grade level contains two textbooks and two exercises books. Our analysis was based on the 2016 version developed for the 2009 mathematics curriculum, which included Mathematics 2.1 (수학 2.1) and Mathematics 2.2 (수학 2.2). According to the teachers' guide in Chapter 6, Book 2.1, ten lessons at the end of the first semester are dedicated to the understanding of simple multiplication concepts in daily life; and in Chapter 2, Book 2.2, twelve lessons in the second semester are dedicated to the teaching of multiplication facts and the operation of single digit multiplication. Within the twelve lessons, eight are allocated to the teaching of multiplication facts, and the rest of the lessons focus on identifying patterns of multiplication. The concept of division is taught starting from third grade.

Our analysis consisted of three stages: First, we examined the two Korean number systems and their number words from the linguistic perspective - the morphology and syntactic (or grammatical) category of Korean numerals, i.e. whether numbers operate as nouns, verbs or adjectives. These categories generally form a larger phrasal category having a distinctive structure, i.e. from a noun to noun phrase, which can act as a complete subject, object, etc. in a sentence, e.g. "three children", "four cookies". And since Korean is a numeral classifier language, we analysed the structural features of the number construction, i.e. noun-numeral-classifier, 어린이 (child) 3 명 and 쿠키 (cookie) 4 개, and the usages and conditions for selecting classifiers. Second, we analysed the morphology and syntax of number sentences in the multiplication tables, written in Chinese characters and Hangul (한글), the Korean alphabet. This provided us insight into how these sentences are being used when students make sense of abstract concepts. Third, we studied the content and the organization of the second grade textbooks and teachers' guides along with specific mathematical ideas on the concept of multiplication and its operation. We identified certain quantifiable characteristics, including the number of suggested lessons where multiplication concepts and 
Table 2. Korean Numerals

\begin{tabular}{|c|c|c|c|c|}
\hline & Sino-Korean numerals & Pronunciations & Native numerals & Pronunciations \\
\hline 1 & 일 & il & 하나 & hana \\
\hline 2 & 이 & $i$ & 둘 & dul \\
\hline 3 & 삼 & sam & 셋 & set \\
\hline 4 & 사 & sa & 넷 & net \\
\hline 5 & 오 & 0 & 다섯 & daseot \\
\hline 6 & 육 & $y u k$ & 여섯 & yeoseot \\
\hline 7 & 칠 & chil & 일곱 & ilgop \\
\hline 8 & 팔 & pal & 여덟 & yeodeol \\
\hline 9 & 구 & $g u$ & 아홉 & ahop \\
\hline 10 & 십 & $\operatorname{sip}$ & 열 & yeol \\
\hline 11 & 십일 & sib-il & 열 하나 & yeol-hana \\
\hline 12 & 십이 & $s i b-i$ & 열 둘 & yeol-dul \\
\hline \multicolumn{5}{|l|}{$\ldots$} \\
\hline 20 & 이십 & $i$-sip & 스물 & seumul \\
\hline 30 & 삼십 & sam-sip & 서른 & seoreun \\
\hline 40 & 사십 & sa-sip & 마흔 & maheun \\
\hline 50 & 오십 & o-sip & 쉰 & swin \\
\hline 60 & 육십 & yuk-sip & 예순 & yesun \\
\hline 70 & 칠십 & chil-sip & 일흔 & ilheun \\
\hline 80 & 팔십 & pal-sip & 여든 & yeodeun \\
\hline 90 & 구십 & gu-sip & 아흔 & aheun \\
\hline 100 & 백 & baek & - & - \\
\hline
\end{tabular}

ideas are introduced and developed. We were particularly interested in language used in the teaching and learning of multiplication. We examined the problem situations in a variety of contexts in which multiplication operations can be applied, since it is believed that the distinctions between classes of multiplication situations are important pedagogically and provide an analytical framework useful for guiding research (Greer, 1992). We investigated the mathematical terms and the semantic features in the word problems. We also compared the verbal expression of mathematical notations $\times$, and the syntax of the multiplication sentences in Korean and English languages. We explored the linguistic features of the language of multiplication and the possible effect on the understanding of the properties and relationships of the operation. We also tried to point out some of the complexities and ambiguities in English, and identified some common difficulties that may be experienced by English-speaking students.

\section{FINDINGS: KOREAN NUMBER SYTEMS AND THE MULTIPLICATION TABLES}

\section{Korean Number Systems and Number Words}

There are two systems of numbers in Korea (see Table 2): one of Chinese origin, namely the Sino-Korean, usually used for cardinal numbers, large numbers and calculation. Similar to the original system, the number formation in Sino-Korea is regular and apparent when compared with English, which explicitly corresponds to the base-ten composition of the number. Sino-Korean number words above 10 are generated by consistent rules, and the literal translation of 'eleven' and 'twelve' into Korean corresponds to '십 일' ten-one and '십이' ten-two, indicating their composition of the decade value and unit value. The number words are also regular for the decade words such '이십' two-ten, '삼십' three-ten for twenty and thirty; multiplies of ten are simple juxtapositions. SinoKorean numerals start from one and go all the way to one hundred million '억 (億)' and to trillion '조 (兆)'. The other number system is native in origin, the native numerals are also structured as '열 하나' ten-one, '열 둘' tentwo and so on. Both are base-ten systems, but one can only count to 99 '아흔 아홉’ using native numerals; Past that number one must count by making use of Sino-Korean numerals. Hence, native numerals are usually used for small numbers such as counting and telling one's own or other people's age.

As can be seen from Table 2, the native numerals are less regular than Sino-Korean with one to two syllables, yet they are more regular when compared with English. According to Lee \& Ramsey (2000), Sino-Korean is 
ordinarily preferred when making mathematical calculation, as in $3+3=6$, read as 삼 (더하기) 삼 (은) 육 (sam tehaki sam un yuk). There are restrictions and considerations to bear in mind when choosing between native Korean and Sino-Korean numerals and Korean students need to use both number systems in dealing with school mathematics and their daily life. For instance, the answer to the question $3+3=6$, where all the values are purely numerical, would be expressed in Sino-Korean 삼 (sam) and 육 (yuk). But if you replace the numerical 3 with a question about the total number of apples, the answer to the question would no longer 육 (yuk) but 여섯 (yeoseot), a native Korean number. Also, if you want to say "the double of three is six" - 3의 2 배는 6 입니다, it is spoken where 삼 (sam) and 육 (yuk) are Sino-Korean numbers but 두 ( $(u l)$, a native Korean number, is used instead of 이 (i) (which will be discussed in later section). In addition, numbers written in Arabic numerals are regularly read as Sino-Korea. The Sino-Korean number names embedded with the base-ten principle that underlies the structure of Arabic numerals is a feature of the representational system, not a fundamental mathematics fact; it is, however, incorporated into many of the algorithms student learn for performing arithmetic, thus it is a powerful concept in their mathematical development.

\title{
The Morphology of Korean Numerals
}

\begin{abstract}
Nouns
In the Korean language, the grammatical functions are expressed by attaching case particles or other various role-marking particles, which indicate the roles of noun phases with respect to the event described by the verb or the state of condition expressed by the adjectives. Therefore, Korean numerals are similar enough to be classed together with nouns and pronouns (Lee \& Ramsey, 2000). Nouns in Korean are normally not marked for number (i.e. singular or plural). The plural making 들 -tul in Korean is said to occur mainly with human nouns, less frequently with non-human animate nouns and far less frequently with inanimate noun (Song, 2005). In English, on the other hand, it is absolutely necessary to mark nouns for number, and to indicate explicitly (that is, by means of $-s$ or $-e s$ ) whether one is talking about one person, or two or more persons, a bus or two or more buses, and so on. When nouns in Korean are preceded by plural numerals such as '삼' three, plural marking is regarded as completely redundant and not used at all.
\end{abstract}

\section{Classifiers}

In Korean grammars, there are types of nouns that do not appear independently in the sentence, and one type of bound noun is the classifier. It is chosen strictly by the type of noun being counted because noun and classifier must always be in agreement. In English, numerals are freely used in conjunction with nouns alone to indicate the number or amount of entities being spoken of. For example, one can say two books or three people. But in Korean, one must say '책 두 권' (book + 2-bound volumes), and '사람 세 명' (people + three-person); the classifier (CL) 권 (kwon) must be used in order to express what is being counted, which is characteristics of bounded volumes such as a book. Nouns must always co-exist with an appropriate classifier for the purpose of counting. For example, it is grammatically wrong to use '권 (kwon)' instead of '명 (myeong)' to express the number of people. There are a fair number of classifiers in Korean, which can be categorised into several types according to semantic concepts such as animacy, shape, and function (Adams \& Conklin, 1973). The use of classifiers is illustrated in Figure 1. This multiplicative situation is the most important class known as "equal groups", in which the number of objects within each group is the same, and normally constitutes a student's earliest encounter with multiplication (Greer, 1992). The multiplicand is the set of the groups, the multiplier indicates how many groups there are, and the product is a collection of equal groups. This word problem in Korean would be translated into English as: 


\section{2 의 단 곱셈구구를 알 수 있어요} 익힘책 27 쪽

동호는 제 I 전시관에 들어섰어요. 전시되어 있는 사슴벌레의 수를 알아보는 방법을 이야기해 봅시다.

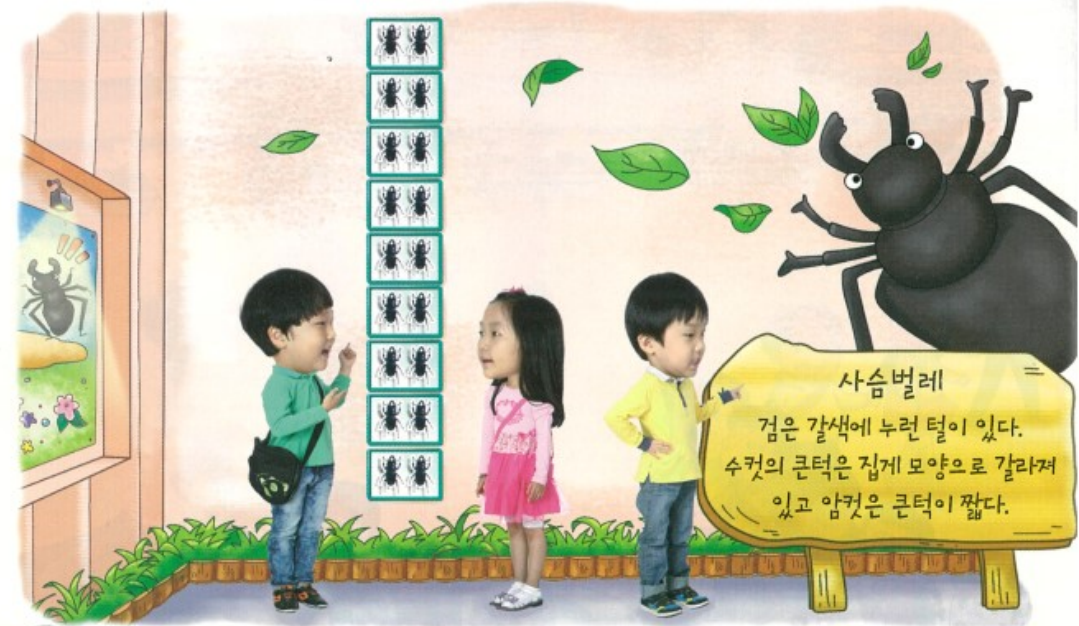

액자 | 개에는 사슴벌레가 2마리씩 전시되어 있습니다. 사슴 벌레의 수를 알아보시오.

- 액자 | 개에 전시되어 있는 사슴벌레는 몇 마리입니까?

$$
2 \times 1=\square
$$

- 액자 2개에 전시되어 있는 사슴벌레는 몇 마리입니까?

$$
2 \times 2=\square
$$

- 액자 5 개에 전시되어 있는 사슴벌레는 몇 마리입니까?

$$
2 \times 5=\square
$$

Figure 1. Multiplication of 2 , the equal groups situation

There are two beetles (mali) in each frame (gae).

How many beetles (mali) in 1 frame (gae)?

How many beetles (mali) in 2 frames (gae)?

How many beetles (mali) in 5 frames (gae)?

In this situation, the number of beetles in each frame is the multiplicand and the number of frames is the multiplier. The number construction is Noun-Number-Classifier (CL), 사슴벌레 2 마리 (beetle 2 CL.animal) and 액자 1 개 (frame 1 CL.piece). The two numbers play clearly different roles with different classifiers; in the case of animals, the prototypical numerical classifier is 마리 (mali), and 개 (gae) belongs to the numerical classifiers for inanimate entities. According to the teacher's guide, a classifier is required in answering these word problems, i.e. $n$ 마리입니다 ( $n$ CL.animal).

$\begin{array}{cccccc}\text { multiplicand } & \times & \text { multiplier } & = & & \text { product } \\ 2 & \times & 1 & = & 2 & \text { 마리입니다 } \\ 2 & \times & 2 & = & 4 & \text { 마리입니다 } \\ 2 & \times & 5 & = & 10 & \text { 마리입니다 }\end{array}$


Table 3. Korean Numeral Classifiers

\begin{tabular}{|c|c|c|c|c|}
\hline Sematic class & Numeral classifier & Original meeting & Gloss & Examples \\
\hline \multirow{2}{*}{ Human } & \multirow{2}{*}{ 명(myeong) } & \multirow{2}{*}{ name } & \multirow{2}{*}{ CL.name } & 학생은 몇 명입니까? \\
\hline & & & & 사람은 몇 명입니까? \\
\hline Animals & 마리(mali) & head & CL.animal & 나비는 몇 마리입니까? \\
\hline \multirow[t]{2}{*}{ Plants } & 송이 (songi) & blossom & CL.blossom & 꽃은 몇 송이입니까? \\
\hline & 개(gae) & piece & CL.piece & 토마토는 모두 몇 개일까요? \\
\hline Inanimate entities & & & & $\begin{array}{c}\text { 음료수는 몇 개인지 곱셈식으로 } \\
\text { 알아보시오. }\end{array}$ \\
\hline
\end{tabular}

Korean students are always taught, and repeatedly insisted upon, to write multiplicand before multiplier; even after the commutative law has been introduced, the order of the multiplication sentence stays the same. As we can see, when the multiplier is increased by 1 개 (gae), the product is increased by the multiplicand 2 마리 (mali), i.e. it is clear that the number of 마리 (mali) increased by adding each 개 (gae), and the product always has the same classifier as the multiplicand. Kaput $(1985$, p.13) asserts that "elementary mathematics of school should not be, as tacitly assumed, exclusively the mathematics of number with applications regarded as separate, but rather should begin with the mathematics of quantity, so that the mathematics and its application are of a piece from the very beginning". This was elaborated upon by Greer (1992, p. 284): "thus attention should be paid not simply to the numbers in a problem but also to the referents of the numbers". Miura and Okamoto (2003) believe the use of numeral classifiers in Japanese makes the referent clear, and provides a stronger visual representation of what the problem is asking. When numbers refer to objects in a situation, for example 두 마리 (two-animal), and 다섯 개 (five-piece), they make much more sense to students than when they do not refer to anything at all. Classifiers which are categorical in natural, when suffixed to numerals, provide students with a meaning for the numbers. Hence, students would have a better sense of different numbers in the multiplicative situation and what they need to do in order to solve the word problem. Classifiers are used extensively throughout the textbooks, particularly when solving word problems. Wherever objects are counted, an appropriate classifier must be selected according to its semantic property; i.e. the classifiers have a paradigmatic relationship. The use of correct classifiers is considered to be related to student's cognitive development based on the semantic features of objects (e.g. Lee, 1997; Uchida \& Imai, 1996). Students must be aware which classifier goes with which noun; examples of different classifiers used in multiplication word problems are shown in Table 3.

As we have mentioned earlier, the difference between singular and plural is not reflected in the noun or in any morphological form. Whether one says 'one butterfly' 한 마리 (1-CL.animal) or 'ten butterflies' 열 마리 (10CL.animal) or we say 'one rose' 한 송이 (1-CL.blossom) or 'ten roses' 열 송이 (10-CL.blossom), the form of the noun does not change as there is no plural marking for classifiers.

\section{The Ancient Multiplication Tables}

$3 \times 4=12$ can be read as three multiplied by four is twelve, or three times four is twelve, or four threes are twelve in English. It can be read as さんし じゅうに (sann shi jyuni) in Japanese, 三四ー十二 (saam sei yat sahp yih) in Chinese, and 삼 사 십이 (sam sa sip il) in Korean. The pronunciations of these East Asian languages sound very similar, and these sentences can be literally translated as "three four ten-two", which is a sequence of numbers without any indication of the multiplication operation.

Gugudan was first written in Chinese characters (see Figure 2) using the Sino-Korean number system. In the Hangul version used today in Korea, only number words and topic particles (TOPIC)은/는 (un/ nun) are included, and they are short single-syllable words that can be chanted like a children's rhyme There is no multiplication symbol nor any indication of the arithmetic operation. Gugudan consists of short sentences of number sequences. When read (see Table 4), for example, $2 \times 1=2$ is 이 일은 이 ( $i$ il un i), two-one-TOPIC-two, which is the same as the multiplication sentence in Arabic numerals, only without the symbols. 은/는 is the topic particle that is attached to a noun to indicate the subject of the sentence. According to Song (2005, pp. 145), "it is generally well understood to have a topic marking function, but in reality this topic marking function alone does not explain everything it does in natural discourse". This topic particle is used mainly in multiplication tables of smaller numbers, such as 2 and 3 , and becomes obsolete when the product is larger than ten, i.e. more than one single syllable. Therefore, we may assume that the use of a topic particle here is due to a phonological reason. Gugudan is both a spoken and written 


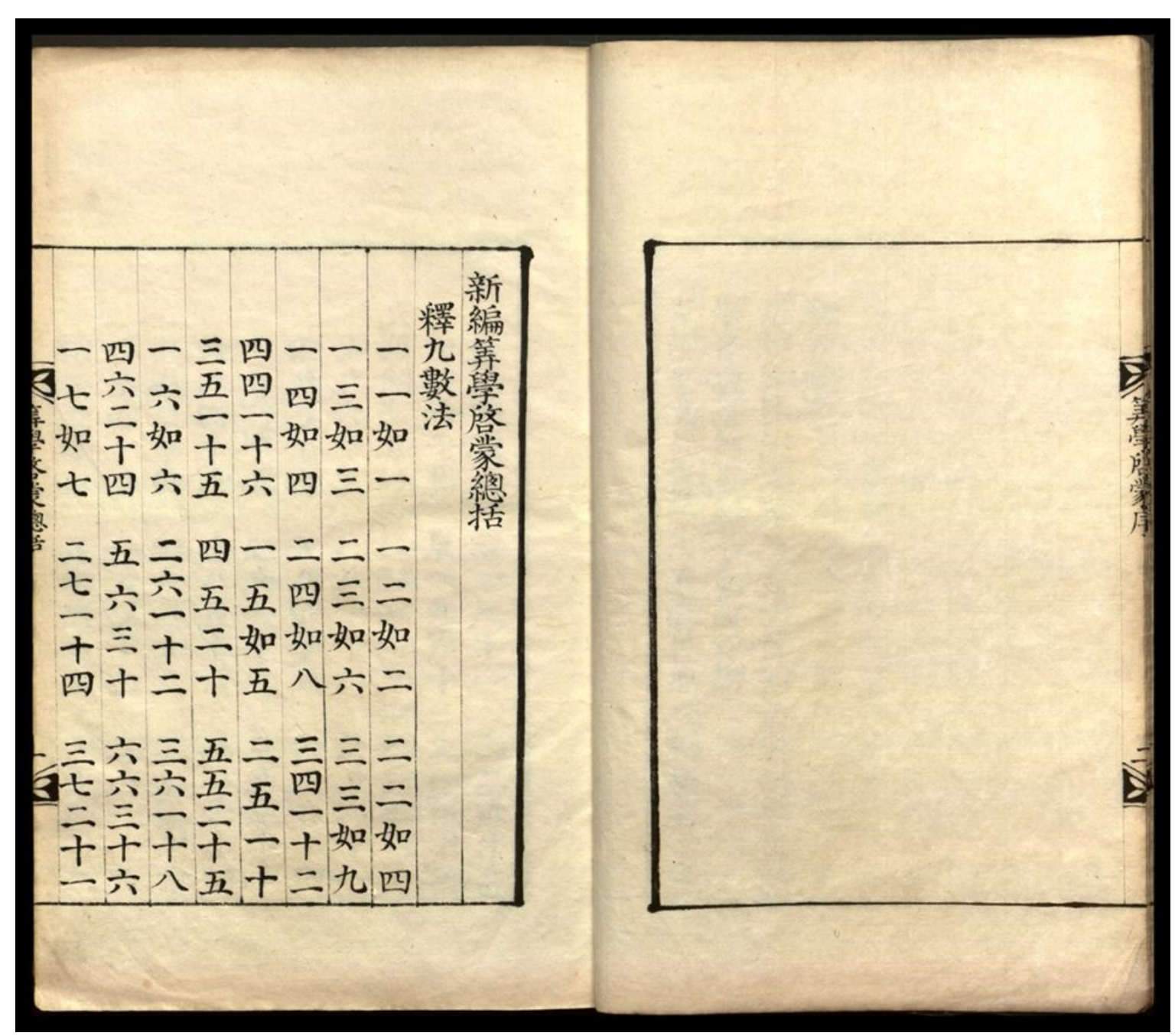

Figure 2a. Introduction to Mathematical Studies 신편산학계몽총괄

language; it is a way of expressing multiplication in the Korean language. It is a set of codes which is embedded in the symbolic construal of language, and only those with this knowledge would be able to decode its use, i.e. it is a cultural artefact and mathematical tool that is only shared by the Korean society. In contrast, there are several ways to read the multiplication tables in English, for examples "One two is two; two twos are four ..." noticed that the sequence of the number is the reverse of the multiplication sentences in the table. Another way of reading the table is "two times one is one; two times two is four..." There is no standard way of reading the set of tables, the choice depends on the users. Therefore, the simplicity and regularity of the Sino-Korea number words and the syntax of Gugudan require less cognitive load from students, which reduce working memory in reciting and recalling multiplication facts.

This linguistic feature of plural marking can be recognised when we read the multiplication tables in Korean and English. For example, $2 \times 6=12$ is read as "two sixes are twelve". The numeral is used in conjunction with nouns to indicate the number of the entities being spoken of; in this case, two sixes. Nouns are made plural by adding a es to the end of the word six, to emphases the quantity of six. Another way of reading it is "two times six is twelve", which indicates the arithmetic operation "times", a verb. The grammatical structures are different in describing the same multiplication sentence. Plural marking is not used in Korean, $2 \times 6$ is read as 이 육 십이 ( $i$ yuk sip i), which simply means two six ten-two, a sequence of numbers. 
不慜䥾楊辟書質淺余重 通過簡輝蒙於問近少利 一牛而非於令歲之也等 見殆且但地金丁法嘗學 而不備字部溝酉如留辟 解可䆵多畣嶈居九意棠 之辨是豕是令夏章等序 手令等客慶鄭抱六學 圖大家術善君病解而 而興之亦徴瀁無微東 補縣拍舍較又外妙國 其監要易其得事之所 缺任第趨同適術傅 其君其歎異國得鮮不 後澽末不究初抄有過展加 偶於端㑑其印本解詳 得街二初源本楊者明 一無紙學流等輝無等 㧙所漫㔯則學算可書

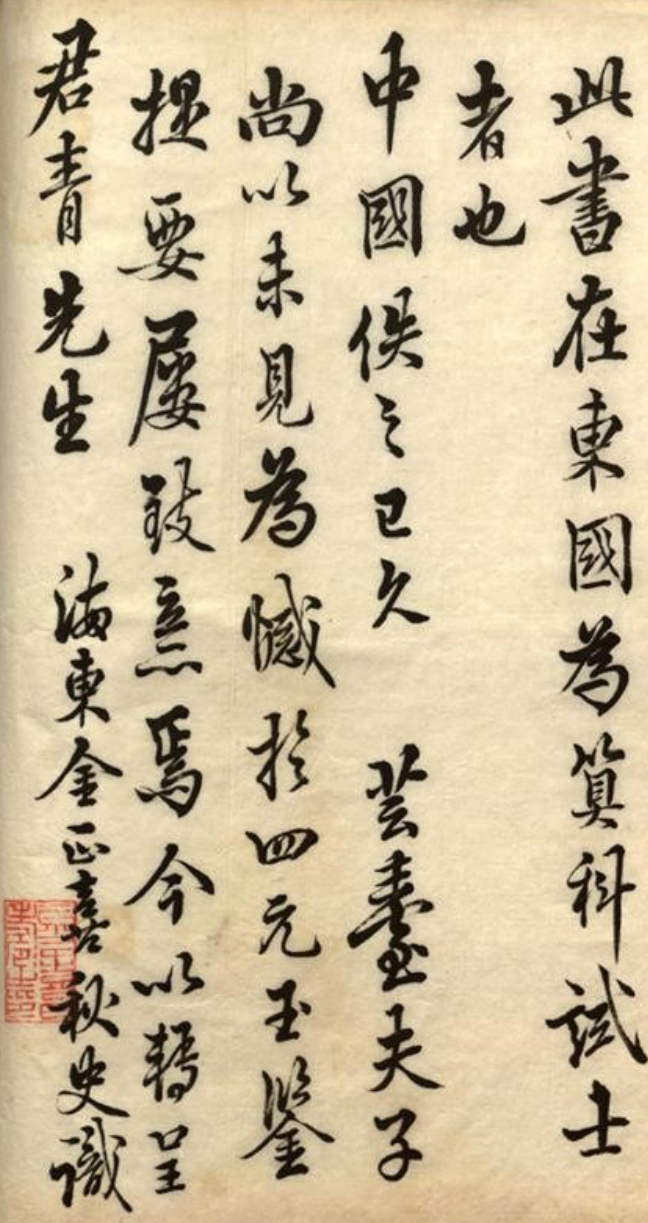

Figure 2b. Introduction to Mathematical Studies 신편산학계몽총괄

Table 4. Two Times Table

\begin{tabular}{cccc}
\hline & 신편 산학계몽 총괄 & 구구단 & Times table of two \\
\hline $2 \times 1=2$ & 二一如二 & 이 일은 이 & One two is two $(1 \times 2=2)$ \\
\hline $2 \times 2=4$ & 二二如四 & 이 이는 사 & Two twos are four $(2 \times 2=4)$ \\
\hline $2 \times 3=6$ & 二三如六 & 이 삼은 육 & Three twos are $\operatorname{six}(3 \times 2=6)$ \\
\hline $2 \times 4=8$ & 二四如八 & 이 사는 팔 & Four twos are eight $(4 \times 2=8)$ \\
\hline $2 \times 5=10$ & 二五一十 & 이 오는 십 & Five twos are ten $(5 \times 2=10)$ \\
\hline $2 \times 6=12$ & 二六一十二 & 이 육 십이 & Six twos are twelve $(6 \times 2=12)$ \\
\hline $2 \times 7=14$ & 二七一十四 & 이 칠 십사 & Seven twos are fourteen $(7 \times 2=14)$ \\
\hline $2 \times 8=16$ & 二八ー十六 & 이 팔 십육 & Eight twos are sixteen $(8 \times 2=16)$ \\
\hline $2 \times 9=18$ & 二九ー十八 & 이 구 십팔 & Nine twos are eighteen $(9 \times 2=18)$ \\
\hline
\end{tabular}

\section{FINDINGS: THE LEXICOGRAMMATICAL AND SEMANTICS FEATURES OF THE LANGUAGE OF MULTIPLICATION}

Mathematics register is a way of using language to express concepts and ideas. It is believed that the uses of ambiguous words in mathematics education, including classroom interaction and written materials, may contribute to students' poor performance and anxiety in mathematics (Durkin \& Shire, 1991). The vocabulary of the mathematical registers used in describing the operations of multiplication may have different meanings in 


\section{윤서와 친구들이 구슬 놀이를 하고 있어요.}

몇의 몇 배를 알아봅시다.
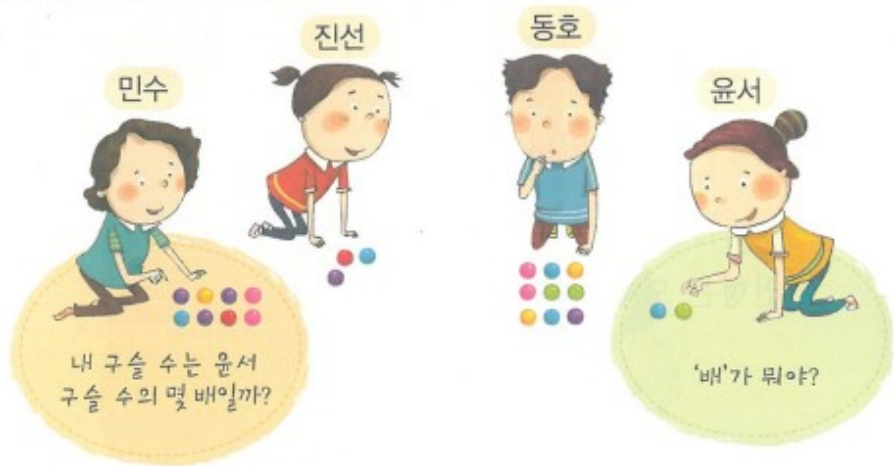

민수가 가진 구슬은 윤서가 가진 구슬의 몇 배인지 알아보시오.
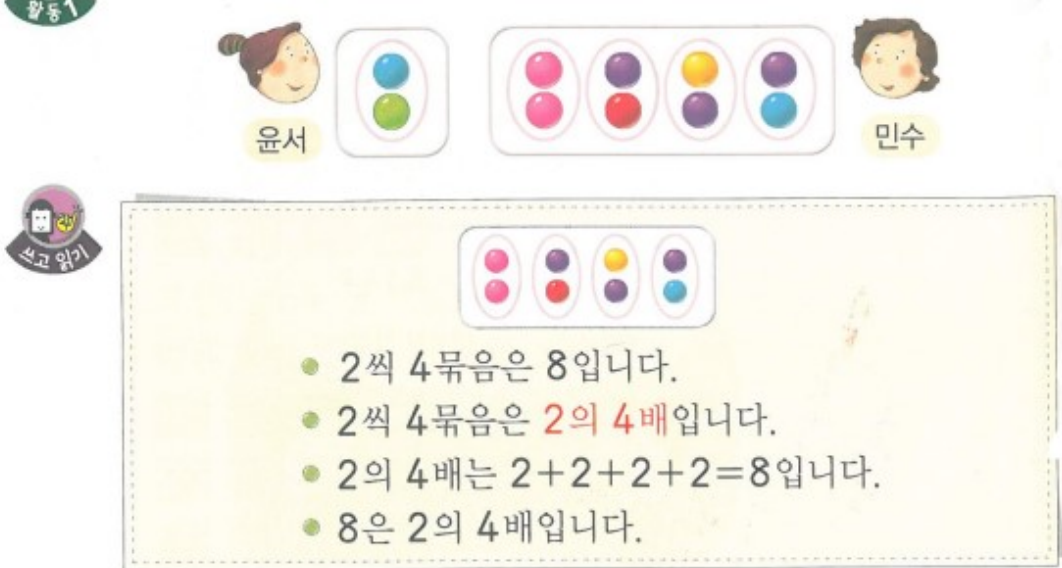

Figure 3. Bae 배, the multiplicative situation

mathematical language and natural language. For example, the Korean word 배 (bae) means ship or stomach but 두 배 (dul bae) means double. The syntax in framing the mathematical problems and the way we express the multiplication symbol also play an important role in the language of multiplication.

\section{Vocabulary}

Multiplicative comparison (Greer, 1992) is another type of multiplicative situation presented in the textbook, verbally expressed by " $n$ times as many as" of two quantities of any type. In this example (see Figure 3), Yoonseo 윤서 has 2 marbles. Minsu 민수 has 4 times as many marbles as Yoonseo. How many marbles does Minsu have? The notion of bae배 is the same as multiples (배수 in Korean) and it is introduced before the learning of multiplication facts. For example, "2의 4 배는 8" means the quadruple of 2 is 8 . Bae 배 does not have an equivalent when translated into English but roughly means "times as much / many as", where 두 배 (dul bae) means double, 세 배 (set bae) means triple, 네 배 (net bae) means quadruple, 다섯 배 (daseot bae) means quintuple etc. A native numeral must be attached to the suffix, bae, which distinguishes the number of the multiplicative factor in the sentence. In this case, the relationship of the two quantities is represented by a native numeral 네 (net), 네 배 (net bae) 4 times, while the other two numbers 2 and 8 are represented by Sino-Korean 이 (i) and 팔 (pal). This highlights the multiplicative factor of the two quantities in the number sentence when speaking verbally. The mathematical term bae 배 helps students to connect the idea of the multiplicative factor, and to conceptualise the thinking about the multiplicative situations in quantifiable terms. In contrast, the English terms: double, triple, quadruple, quintuple etc. have their prefixes taken from Latin names of the numerals, and the suffix, -ple originated from Medieval Latin, meaning more. These meanings are unclear to students when they come across these linguistic features for the first time. 
Table 5. Mathematical Registers

\begin{tabular}{|c|c|c|c|c|c|}
\hline \multicolumn{3}{|c|}{ Tuple } & \multicolumn{3}{|c|}{ Shapes } \\
\hline Single & & & & & \\
\hline Double & 두 배 & dul bae & & & \\
\hline Triple & 세 배 & set bae & Triangle & 삼각형 & sam kakhyeong \\
\hline Quadruple & 네 배 & net bae & Quadrilateral & 사각형 & sa kakhyeong \\
\hline Quintuple & 다섯 배 & daseot bae & Pentagon & 오각형 & o kakhyeong \\
\hline Hextuple & 여섯 배 & yeoseot bae & Hexagon & 육각형 & yuk kakhyeong \\
\hline Septuple & 일곱 배 & ilgop bae & Heptagon & 칠각형 & chil kakhyeong \\
\hline Octuple & 여덟 배 & yeodeol bae & Octagon & 팔각형 & pal kakhyeong \\
\hline Nonuple & 아홉 배 & ahop bae & Nonagon & 구각형 & gu kakhyeong \\
\hline Decuple & 열 배 & yeol bae & Decagon & 십각형 & sip kakhyeong \\
\hline
\end{tabular}

According to Halliday (1978), mathematical registers can be developed by reinterpreting existing everyday words with specific mathematics meaning. For example, in Korean, the naming of geometrical figures, triangle (삼각형: sam kakhyeong ) and quadrilateral (사각형: sa kakhyeong) can be literally translated as "three-corner-shape" and "four-corner-shape", where an everyday word such as corner is used, and explicitly denoting the features of the triangle and the quadrilateral and how the shapes are named (see Table 5). In the case of multiplication, the word bae 배 produces clarity by using compound words to present multiplicative comparison situations. This helps students to focus on the nature of the relationship between two quantities rather than the specific arithmetic operations. Also, notice that the numerals used for verbal expression in this case is native Korean, which can be easily distinguished from other numbers in the sentences. The use of bai (ばい) as an interpretation for multiplication can also be found in a Japanese textbook series (Watanabe, 2003), indicating the language differences between English and East Asian languages.

\section{Symbol $\times$ and Syntax}

\section{The interpretation of symbolic expressions}

When the multiplication symbol ' $x$ ' is introduced, a decision must be made over the precise verbal interpretation that is to be used if ambiguity is to be avoid. $3 \times 4$, meaning four groups of three (see Figure 4), is read as 삼 (곱하기) 사 (sam kop-haki sa) in Korean. 곱하기 (kop-haki) is the only term used to represented the operation of multiplication. In contrast, there are many different interpretations of the multiplication symbol in English language, as explained in Anghileri's "The language of multiplication and division" (1991). For example, when one says ' 3 times 4 ', which refers to a group of 4 elements taken 3 times (i.e. $4+4+4$ ), can also be said as: 3 groups of 4,3 fours, 3 by 4 . However, the same multiplication sentence $3 \times 4$ can also be said as ' 3 multiplied by 4 ' which refers to a group of 3 elements taken 4 times, 4 groups of 3 (i.e. $3+3+3+3$ ). In fact, ' 3 times 4 ' and ' 3 multiplied by 4 ', represents an active and passive constructions respectively, which signify different multiplicative situations. First ' 3 times 4 ' can be illustrated as ' 3 children have 4 cookies each. How many cookies do they have altogether?' (Greer, 1992). This problem can naturally be conceived as 3 groups of 4 , where the number of cookies represents the multiplicand that is repeatedly summed up, and the number of children represents the multiplier which is the number of times the multiplicand must be successively added, i.e. $3 \times 4=12$. Note that, the multiplier is usually written before the multiplicand in the English speaking world, which appears to be based on the language, since it seems to be more natural to interpret this as " 3 times" of a group of 4 . As we can see, the two numbers play different roles which are attached to different referents in problem content (Kaput, 1985). According to Greer (1992), this is known as the asymmetrical situations where the multiplier and multiplicand can be distinguished. In "equal groups" situation, the number of objects in each group is the multiplicand and the number of groups is the multiplier. Unlike the commutative relationship which exists between two numbers in a numerical multiplication, the numbers in a word problem cannot be reversed without changing the meaning of the problem. Consequently, multiplication is psychologically non-commutative in a problem solving context (Mangan, 1986). Hence, the position of the multiplier and multiplicand of the number sentence matter if we are dealing with asymmetrical multiplication situations. When the student understands the communicate rule for multiplication, $3 \times 4$ and $4 \times 3$ generates the same product, the discrepancy between the two expressions will be less important. But for the student struggling to attach some meaning to symbolic arithmetic expressions, the ambiguity may present a considerable barrier to understanding. A consequence of the asymmetrical situation is that two types of division may be 

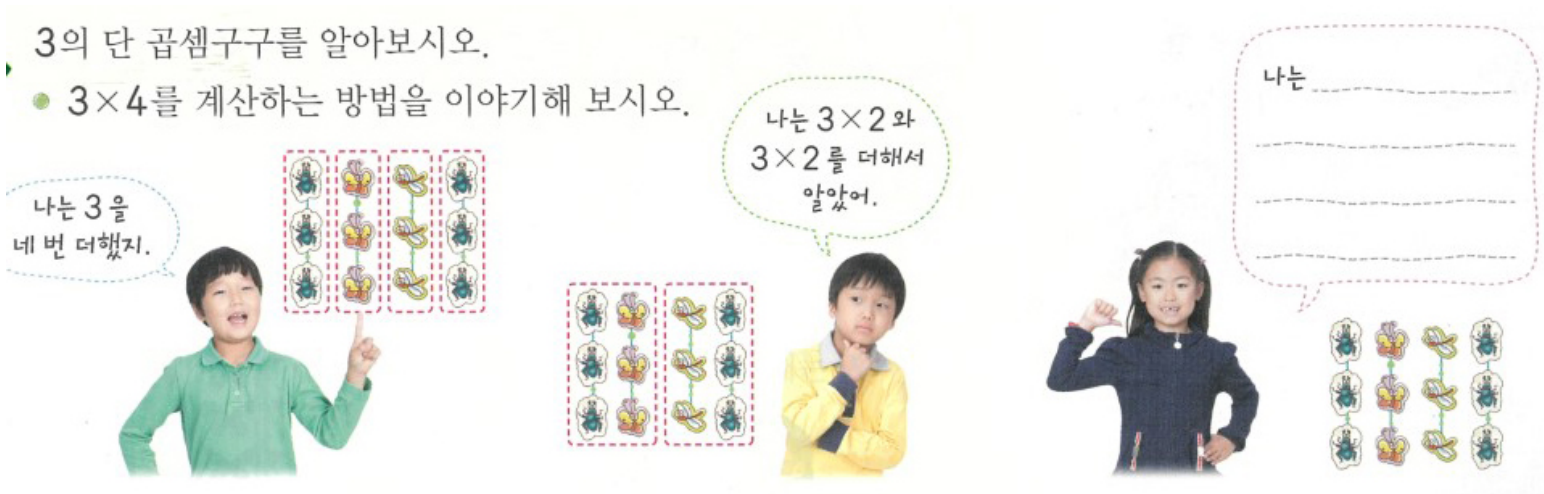

Figure 4. Multiplication of 3, equal groups situation

distinguished. Dividing the total by the number of groups to find the number in each group is called partitive division, which corresponds to the familiar practice of equal sharing. For example: 12 cookies are shared equally among 3 children (multiplier), how many does each one get? Dividing the total by the number of each group to find the number of group is called quotitive division. For example: if you have 12 cookies, how many children can give 4 cookies (multiplicand) (Greer, 1992)? Understanding precisely the implication of a variety of phases and emphasising the distinction between multiplicand and multiplier are essential if students are to interpret correctly multiplicative situations that they later meet. This also gives students a better foundation for later development in multiplicative concepts such as part-whole relationships and fractions.

\section{Active and passive constructions}

As discussed, 'multiply by' and 'multiplied by' refers to different multiplication situations. According to Beilin (1975), active sentence forms are easier than passive sentence forms in both their comprehension and their production. Hence, the word 'times' is more popular than 'multiplied by' in the language of multiplication. Hence, 3 times 4 may appear to children to be an easier construction to understand than 4 multiplied by 3 , the more formal language of multiplication. Lee (2006) believed that it is often the syntax of the conventional style that causes problems for students engaging with mathematics. The use of the passive voice and deletion of personal pronouns is a feature of mathematical discourse and these contribute to the 'distant authorial voice' (Morgan, 1995, p. 14) which is common in mathematical texts. For example, the area of a rectangle is equal to the length $(3 \mathrm{~cm})$ multiplied by the width $(4 \mathrm{~cm})$. She also pointed out that "using the passive voice in mathematics, when pupils are unfamiliar and inexpert users of it in English language lessons, is another barrier to pupils feeling that they are able to read about and use mathematical concepts." Passive voice is not used in the language of multiplication in Korean.

\section{Semantics of Multiplication Language}

As we have mentioned earlier, students in Korea are taught always to write the multiplicand (the size of a group) before the multiplier (the number of groups). But in the English speaking world, the multiplier is usually placed before the multiplicand, see Figure 5 for example, which is opposite to the Korean notation. The Korean way by putting the size of a group first then the number of groups is the same as how they read the multiplication tables, and this makes it easier for students to recall multiplication facts to solve problems. Although Korean emphasises the role of the multiplicand and multiplier explicitly, the commutative property is investigated after the learning of basic facts of $2 \mathrm{~s}, 5 \mathrm{~s}$ and 3s. In Figure 6, the butterflies are arranged in a rectangular array with rows and columns, and we say it is a 3 by 4 array, while the terms 'row' and 'column' may present difficulties in English (Anghileri, 1991). In Korean, the word 줄 (chul) literally means 'a line', and is used to represent both 'row' and 'column'. The two numbers multiplied play equivalent roles, and they are not distinguishable as multiplicand and multiplier. If we recall the fact families of $4 \mathrm{~s}$ and $5 \mathrm{~s}$ : 
directly reflect the base-ten nature are regular and transparent, and the dual systems are used interchangeably. Our findings have showed that these systems give students the referents of the numbers in context, whether they are referring to numerals, quantities, or even relationships between quantities. The ancient multiplication table Gugudan, written in Sino-Korean numerals- have single-syllable number words and simple sentence - Structure that is easy to understand and memorise. The lack of plural marking and passive voice also make the multiplication tables, as well as mathematical texts in multiplication, straightforward and less ambiguous. The use of classifiers in word problems makes the referent clear, increases coherence to the objects and assigns them to a set, which helps the students to visualize what the problem is asking for, whether it is the number of animals 마리 (mali) or the number of people 명 (myeong). We have also identified other distinguishable features, including the mathematical term, Bae배, which can also be found in Chinese and Japanese languages to represent multiplicative comparison situations. Here, a native Korean numeral is used to represent the multiplicative factor, which can be conceived as the multiplier. It can be differentiated easily from other numerals in the mathematical texts or word problems. We believe the use of bae배 has greater impact on students' development of multiplicative concepts. Bae 배 represents a constant relation of one-to-many correspondence between two sets, the invariant relationship between two quantities. By emphasizing this multiplicative factor, or constant, at an early stage may help students in making the transition from multiplicative reasoning to proportion reasoning, such as rate and ratio. Moreover, we believe the results reported in this paper have a number of implications for a further development of linguistics study in the learning of mathematics.

First, research in the Learner's Perspective Study (LPS) has made clear just how culturally-situated are the practices of mathematics classrooms around the world; the classroom is a site through which the international mathematics education community can explore considerations of culture, language, temporality and theory (e.g., Clarke, Keitel, \& Shimizu, 2006). However, LPS focuses on the eighth grade, without considering the classroom practices and discourses in elementary schools. In fact, Koreans, Japanese and Chinese have a lot of similarities in terms of the language of mathematics, and many problem solving strategies seem to be common, especially in elementary school mathematics. Hence, we would like to extend our study to reveal the subtle and pervasive effects of culture and language that shape and constitute certain practices as they impinge on students' early mathematics development.

Second, this study strengthens the foundation of our research on language and mathematics education. Although the discussion here is of limited scope and does not give a complete account of the language instruction of multiplication, our findings provided us with the basis for our wider study on Korean classroom, and to extend our understanding of how language, cultural practices and sociocultural processes may influence students' learning. The documented data served to ground the research in the context of our wider investigation. Information contained in these documents suggested the teaching sequences and strategies that needed to be observed. Results from the document analysis are particularly useful in understanding classroom discourses. Our empirical data from other studies has shown that most Korean students already acquire some knowledge of multiplication before their formal learning in school. They could memorise multiplication facts through Gugudan related songs and games at home and throughout their kindergarten years. Students solve multiplication problems based on the way Gugudan is written. Therefore, without a good understanding of the linguistic features of Korean numerals and multiplication tables, it would be difficult (if not impossible) to analyse classroom discourses and students' problem solving strategies in the classroom.

Finally, we would like to highlight the importance of language analysis in international comparative studies. TIMSS has provided us with extensive information about educational policies and practices in and across countries. It aims at examining students' competence according to the school curriculum (Leung, 2014), and has the content areas and processes that are typically associated with school mathematics. In the grade 4 assessment, it emphasises items which require the reproduction of facts or standard algorithms, and has a larger number of items focusing on Number and Measurement (Ruddock, Clausen-May, Purple, \& Ager, 2006). These items (which include multiplication, division, ratio, rate, fraction, proportional reasoning) are related to multiplicative conceptual fields defined by Confrey $(1994)$ and Vergnaud $(1983,1988)$. As pointed out in this paper, the forms and constructions of Korean language in the learning of multiplication do not always have exact counterparts in English. The regularity of the number systems and simplicity of mathematical registers may influence Korean students' learning mathematics and hence their mathematics achievement. The interaction between linguistic, conceptual and social aspects of students' learning is complex. Difficulties posed by the language in which mathematics is expressed adversely affect students' conceptualization of mathematical notions. The lack of research in the language of mathematics, in particular TIMSS items, may lead to misinterpretation of the data, and thus care should be taken when translating results from these studies. Previous research on East Asian student achievement in cross-national studies focuses on cultural factors (e.g. Leung, 2001, 2002, 2006), namely the Confucian Heritage Culture (CHC) (Biggs, 1996). Cultural values held by East Asians were believed to be the possible explanation for high student 
achievement. They include a strong emphasis on education and examination culture (Cheng, 1994), belief in effort (Stevenson, 1987), the stress on practice and memorization (Biggs, 1996), and teacher competency and qualification (Leung, 2001; Leung \& Park, 2002) etc. These studies ignore any linguistic factors, both systemic and institutional (Halliday, 1978) that underpin the learning of mathematics. We believe the study of the mathematical functionality of the natural languages, and the possible sources of the linguistics features facing the mathematics learners, requires more attention. In part, why East Asian students performed better in certain domains / items could be studied from linguistic and cultural perspectives.

We wish the research findings in this present study to serve as an important reference for future studies in this under-researched field of the influence of culture and language on mathematics learning and achievement. This study only addresses the treatment of multiplication in the student textbooks and teachers' manuals. Examination of how teachers actually teach and students learn in class are beyond the scope of this study. Although more work needs to be done, our initial findings support our hypothesis that the clarity of the Korean language supports the learning of multiplication.

\section{REFERENCES}

Adams, K. L., \& Conklin, N. F. (1973). Toward a theory of natural classification. Ninth regional meeting of the Chicago Linguistic Society, 9, 1-10.

Allan, K. (1977). Classifiers. Language, 53(2), 285-311. https:/ / doi.org/10.2307/413103

Anghileri, J. (1991). The language of multiplication and division. Durkin, K. and Shire, B. (FAs). Language in Mathematical Education, 95-104. Buckingham: OUP.

Barton, B. (2009). The language of mathematics: Telling mathematical tales. New York: Springer.

Beilin, H. (1975). Studies in the cognitive basis of language development. Academic Press.

Biggs, J. (1996). Western misperceptions of the Confucian-heritage learning culture. The Chinese learner: Cultural, psychological and contextual influences, 45-67. Comparative Education Research Centre, Faculty of Education, University of Hong Kong, Pokfulam Road, Hong Kong; The Australian Council for Educational Research, Ltd., 19 Prospect Hill Road, Camberwell, Melbourne, Victoria 3124, Australia.

Chemla, K. (2008). Zhu Shijie 朱世傑. Encyclopaedia of the History of Science, Technology, and Medicine in Non-Western Cultures, 2359-2360. Springer, Dordrecht. https:/ / doi.org/10.1007/978-1-4020-4425-0_8959

Cheng, K. M. (1994). Quality of education as perceived in the Chinese culture. Takala T. (ed.), Quality of Education in the Context of Culture in Developing Countries, 67-84. Tampere, Finland, Tampere University Press.

Clarke, D. J. (2013). Contingent conceptions of accomplished practice: the cultural specificity of discourse in and about the mathematics classroom. ZDM Mathematics Education, 45(1), 21-33. https:/ / doi.org/10.1007/s11858-012-0452-8

Clarke, D. J., Keitel, C., \& Shimizu, Y. (Eds.). (2006). Mathematics classrooms in twelve countries: The insider's perspective (Vol. 1). Sense publishers.

Confrey, J. (1994). Splitting, similarity, and rate of change: A new approach to multiplication and exponential functions. The development of multiplicative reasoning in the learning of mathematics, 293-330. State University of New York Press.

Downing, P. A. (1996). Numeral classifier systems: The case of Japanese (Vol. 4). John Benjamins Publishing.

Durkin, K. \& Shire, B. (1991). Lexical ambiguity in mathematical context. Language in mathematical education: Research and practice, 72-84. Open University Press.

Fan, L., Wong, N. Y., \& Cai, J. (Eds.). (2015). How Chinese Teach Mathematics (Vol. 6). World Scientific. https:// doi.org/10.1142/9789814415828

Fan, L., Wong, N.-Y., Cai, J., \& Li, S. (Eds.) (2004). How Chinese learn mathematics: perspectives from insiders, Singapore, SG. World Scientific, 592pp.

Fuson, K. C. (1990). Conceptual structures for multiunit numbers: Implications for learning and teaching multidigit addition, subtraction, and place value. Cognition and instruction, 7(4), 343-403. https://doi.org/10.1207/s1532690xci0704_4

Fuson, K. C., \& Kwon, Y. (1991). Chinese-based regular and European irregular systems of number words: The disadvantages for English-speaking children. Language in mathematical education: Research and practice, 211226.

Fuson, K. C., \& Kwon, Y. (1992a). Korean children's single-digit addition and subtraction: Numbers structured by ten. Journal for Research in Mathematics Education, 148-165. https:/ / doi.org/10.2307/749498 
Fuson, K. C., \& Kwon, Y. (1992b). Korean children's understanding of multidigit addition and subtraction. Child development, 63(2), 491-506. https:/ / doi.org/10.1111/j.1467-8624.1992.tb01642.x

Fuson, K. C., \& Li, Y. (2009). Cross-cultural issues in linguistic, visual-quantitative, and written-numeric supports for mathematical thinking. ZDM, 41(6), 793-808. https:/ / doi.org/10.1007/s11858-009-0183-7

Geary, D. C., Bow-Thomas, C. C., Fan, L., \& Siegler, R. S. (1993). Even before formal instruction, Chinese children outperform American children in mental addition. Cognitive Development, 8(4), 517-529. https:/ / doi.org/10.1016/S0885-2014(05)80007-3

Greer, B. (1992). Multiplication and division as models of situations. Handbook of research on mathematics teaching and learning: A project of the National Council of Teachers of Mathematics, 276-295. New York: Macmillan.

Halliday, M. A. K. (1978). Language as social semiotic. Arnold: London.

Her, O. S. (2012). Distinguishing classifiers and measure words: A mathematical perspective and implications. Science Direct, 122(14), 1668-1691. https:/ / doi.org/10.1016/j.lingua.2012.08.012

Her, O. S., Chen, Y. C., \& Yen, N. S. (2018). Neural correlates of quantity processing of Chinese numeral classifiers. Brain and Language, 176, 11-18. https:/ / doi.org/10.1016/j.band1.2017.10.007

Ho, C. S. H., \& Fuson, K. C. (1998). Children's knowledge of teen quantities as tens and ones: Comparisons of Chinese, British, and American kindergartners. Journal of Educational Psychology, 90(3), 536. https:/ / doi.org/10.1037/0022-0663.90.3.536

Ito, H., Kubo-Kawai, N., \& Masataka, N. (2011). The Role of Learning the Japanese Kuku Multiplication Chant in Simple Arithmetic Operations. Creative Education, 2(3), 276. https:/ / doi.org/10.4236/ce.2011.23037

Kaput, J. J. (1985). Multiplicative Word Problems and Intensive Quantities: An Integrated Software Response. Technical Report 85-19. Educational Technology Center, Cambridge, MA.

Kwon, O. N., \& Cho, S. J. (2012). Balance between foundations and creativity: features of Korean mathematics education. ZDM Mathematics Education, 44, 105-108. https:/ / doi.org/10.1007/s11858-012-0409-y

Lee, C. (2006). Language for Learning Mathematics: Assessment for Learning in Practice: Assessment for Learning in Practice. McGraw-Hill Education (UK).

Lee, I., \& Ramsey, S. R. (2000). The Korean Language. Suny Press.

Lee, K. O. (1997). The role of semantic and syntactic knowledge in the first language acquisition of Korean classifiers. Journal of Korean Association of Child Studies, 18-2, 73-85.

Lee, K. O., \& Lee, S. Y. (2009). The acquisition of Korean numeral classifiers. The handbook of East Asian psycholinguistics, 137-149. Cambridge University Press.

LeFevre, J. A., \& Liu, J. (1997). The role of experience in numerical skill: Multiplication performance in adults from Canada and China. Mathematical Cognition, 3(1), 31-62. https:/ / doi.org/10.1080/135467997387470

Leung, F. K. S. (1989). The Chinese Culture and Mathematics Learning. C. Keitel (Ed.) Mathematics, Education, and Society. UNESCO.

Leung, F. K. S. (2001). In search of an East Asian identity in mathematics education. Educational Studies in Mathematics, 47(1), 35-51. https:/ / doi.org/10.1023/A:1017936429620

Leung, F. K. S. (2002). Behind the high achievement of East Asian students. Educational Research and Evaluation, 8(1), 87-108. https://doi.org/10.1076/edre.8.1.87.6920

Leung, F. K. S. (2006). Mathematics Education in East Asia and the West: Does Culture Matter? In F.K.S. Leung, K. D. Graf, \& F. J. Lopex-Real (Eds.), Mathematics Education in Different Cultural Traditions. A Comparative Study of East Asia and the West: The 13th ICMI study (pp. 21-46). Boston, MA: Springer US. https://doi.org/10.1007/0-387-29723-5_2

Leung, F. K. S. (2014). What can and should we learn from international studies of mathematics achievement? Mathematics Education Research Journal, 26(3), 579-605. https://doi.org/10.1007/s13394-0130109-0

Leung, F. K. S., \& Park, K. (2002). Competent students, competent teachers? International Journal of Educational Research, 37(2), 113-129. https:/ / doi.org/10.1016/S0883-0355(02)00055-1

Mangan, C. (1986). Choice of operation in multiplication and division word problems (Unpublished doctoral dissertation), Queen's University, Belfast.

Miller, K. F., \& Stigler, J. W. (1987). Counting in Chinese: Cultural variation in a basic cognitive skill. Cognitive Development, 2(3), 279-305. https:/ / doi.org/10.1016/S0885-2014(87)90091-8

Miller, K. F., Kelly, M., \& Zhou, X. (2005). Learning mathematics in China and the United States. Handbook of mathematical cognition, 163-178. 
Miura, I. T., \& Okamoto, Y. (2003). Language supports for mathematics understanding and performance. A. J. Baroody \& A. Dowker (Eds.), Studies in mathematical thinking and learning. The development of arithmetic concepts and skills: Constructing adaptive expertise, 229-242. Mahwah, NJ: Lawrence Erlbaum Associates.

Miura, I. T., Okamoto, Y., Kim, C. C., Steere, M., \& Fayol, M. (1993). First graders' cognitive representation of number and understanding of place value: Cross-national comparisons: France, Japan, Korea, Sweden, and the United States. Journal of Educational Psychology, 85(1), 24-30. https:/ / doi.org/10.1037/0022-0663.85.1.24

Morgan, C. (1995). An analysis of the discourse of written reports of investigative work in GCSE mathematics (PhD dissertation), Institute of Education, University of London, London.

Morgan, C., Craig, T., Schuette, M., \& Wagner, D. (2014). Language and communication in mathematics education: an overview of research in the field. ZDM, 46(6), 843-853. https://doi.org/10.1007/s11858-014-0624-9

Ng, S. S. N., \& Rao, N. (2010). Chinese number words, culture, and mathematics learning. Review of Educational Research, 80(2), 180-206. https:// doi.org/10.3102/0034654310364764

Pimm, D. (1987). Speaking Mathematically: Communication in Mathematics Classrooms. Language, Education and Society series. Routledge \& Kegan Paul, London and New York.

Ruddock, G., Clausen-May, T., Purple, C., \& Ager, R. (2006). Validation study of the PISA 2000, PISA 2003 and TIMSS-2003 international studies of pupil attainment. Nottingham: Department for Education and Science.

Schleppegrell, M. J. (2007). The linguistic challenges of mathematics teaching and learning: A research review. Reading E Writing Quarterly, 23(2), 139-159. https:/ / doi.org/10.1080/10573560601158461

Solano-Flores, G. (2010). Function and form in research on language and mathematics education. Language and mathematics in education: Multiple perspectives and directions for research, 113-149.

Song, J. J. (2005). The Korean language: Structure, use and context. Routledge.

Song, M., \& Ginsburg, H. P. (1985). The development of informal and formal mathematical knowledge in Korean and American children. Paper presented to the biennial meeting of the Society for Research in Child Development, Toronto.

Song, M., \& Ginsburg, H. P. (1986). The effect of the Korean number system on early mathematics ability. Paper presented to the annual meeting of the American Educational Research Association, San Francisco.

Stephens, A. C., Ellis, A. B., Blanton, M., \& Brizuela, B. M. (2017). Algebra Thinking in the Elementary and Middle Grades. In J. Cai (Ed.), Compendium for research in mathematics education, 421-456. Reston, VA: National Council of Teachers of Mathematics.

Stevenson, H. W. (1987). America's math problems. Educational Leadership, 45(2), 4-10.

Uchida, N., \& Imai, M. (1996). A study on the acquisition of numerical classifiers among young children: The development of human/animal categories and generation of the rule of classifiers applying. Japanese Journal of Educational Psychology, 44(2), 126-135. https:/ / doi.org/10.5926/jjep1953.44.2_126

Vergnaud, G. (1983). Multiplicative structures. Acquisition of mathematics concepts and processes, 127-174. Academic Press.

Vergnaud, G. (1988). Multiplicative structures. Hiebert, J., \& Behr, M. (Eds), Number Concepts and Operations in the Middle Grades, Volume 2. Research Agenda for Mathematics Education, 141-161. National Council of Teachers of Mathematics, 1906 Association Drive, Reston, VA 22091.

Watanabe, T. (2003). Teaching multiplication: An analysis of elementary school mathematics teachers' manuals from Japan and the United States. The Elementary School Journal, 104(2), 111-125. https://doi.org/10.1086/499745

Whorf, B. L., Carroll, J. B., Levinson, S. C., \& Lee, P. (2012). Language, thought, and reality: Selected writings of Benjamin Lee Whorf. Mit Press.

\section{http://www.ejmste.com}

